\title{
Análise psicossocial do preconceito contra homossexuais ${ }^{1}$
}

\author{
Psychosocial analyses of prejudice against homosexuals
}

\author{
Alessandra Ramos Demito FLEURY² \\ Ana Raquel Rosas TORRES ${ }^{2}$
}

\begin{abstract}
Resumo
Estudos a respeito do preconceito e da discriminação realizados em vários países demonstram que esse fenômeno vem assumindo formas cada vez mais sutis. Este trabalho insere-se nesse campo de estudo e investiga os efeitos da orientação sexual no processo de infra-humanização. Dele participaram 135 estudantes de pós-graduação na área de recursos humanos. A eles era solicitado que respondessem um questionário no qual avaliavam indivíduos homossexuais ou heterossexuais, atribuindo-lhes traços naturais e culturais, objetivando verificar a presença do processo de infra-humanização no preconceito contra os homossexuais. Diferentemente de outros estudos na área, os resultados indicaram que o preconceito contra os homossexuais se expressa de forma mais sutil que flagrante, apresentando uma maior atribuição de características positivas para o grupo majoritário e não se diferenciando em termos de atribuição de características negativas para o grupo minoritário. Esses resultados são discutidos, ressaltando-se a importância de mais estudos sobre o tema, tão pouco estudado por psicólogos sociais.
\end{abstract}

Unitermos: homossexualidade; infra-humanização; preconceito; orientação sexual.

\begin{abstract}
Studies about prejudice and discrimination carried out in several countries have demonstrated that such phenomenon is taking more subtle shapes. This work is inserted in this field and investigates sexual orientation effects in the infra-humanization process. Participants were 135 students from the human resources post-graduation course. They had answered a questionnaire that required them to evaluate individuals who could be either homosexuals or heterosexuals by the attribution of natural or cultural characteristics in order to verify the presence of the infra-humanization process in the prejudice against homosexuals. Different from the previous studies, the results indicated that the prejudice against homosexuals is expressed in a more subtle way through the attribution of more positive characteristics to heterosexuals and the attribution of the same level of negative characteristics to both groups of individuals. These results are discussed emphasizing the importance of more studies about the subject which has been neglected by social psychologist.
\end{abstract}

Uniterms: homosexuality; infra-humanization; prejudice, sexual orientation.

Gordon Allport foi um dos pioneiros no estudo do preconceito em Psicologia Social. Sua definição, publicada em 1954, é ainda hoje a mais utilizada nos estudos sobre o tema. Para ele, o preconceito seria "uma atitude evitativa ou hostil contra uma pessoa que pertence a um grupo simplesmente porque ela pertence àquele grupo, e está, portanto, presumido que objetivamente ela tem as qualidades atribuídas ao grupo"3

\section{$\cos$}

1 Artigo elaborado a partir da dissertação de A.R.D. FLEURY, intitulada:"Homossexualidade e preconceito: o que pensam os profissionais de recursos humanos", Universidade Católica de Goiás, 2006.

2 Universidade Católica de Goiás, Departamento de Psicologia. Av. Universitária, 1440, Setor Universitário, 74000-000, Goiânia, GO, Brasil. Correspondência para/Correspondence to: A.R.R. TORRES. E-mail: <arr.torres@gmail.com>.

3 An aversive or hostile attitude toward a person who belongs to a group, simply because he belongs to that group, and is therefore presumed to have the objectionable qualities ascribed to the group. 
(Allport, 1954, p.7). No entanto os estudos atuais têm demonstrado a existência de transformações em sua forma de expressão e da discriminação dela decorrente. Essas transformações assemelham-se às mutações que um vírus pode sofrer para coexistir num ambiente inadequado à sua sobrevivência, promovendo, assim, por meio dessa mutação, sua adaptação ao ambiente hostil, mas não necessariamente sua eliminação. Apesar de um tanto agressiva, essa analogia resume as conclusões tiradas de grande parte dos estudos sobre a expressão de um fenômeno não menos violento, porém muitas vezes mais discreto: o preconceito nas sociedades modernas (Gaertner \& Dovídio, 1986; Pettigrew \& Meertens, 1995; Vala, Brito \& Lopes, 1999). Nessas sociedades ocorreram modificações do ponto de vista social e legal sobre a situação dos grupos minoritários, tendo alguns fatos influenciado preponderantemente essas transformações. A Declaração Universal dos Direitos Humanos, que há mais de 50 anos condena todas as formas de discriminação, além de diversas emendas constitucionais proibindo o preconceito e a discriminação, contribuiu para que as pessoas percebessem que a norma do igualitarismo estava fortemente presente na sociedade e que comportamentos discriminatórios não mais seriam tolerados.

Apesar de esses fatos terem influenciado a percepção das pessoas em relação à expressão do preconceito, eles parecem não ter conseguido verdadeiramente extinguir a expressão do fenômeno. Diversos estudos na Europa e nos Estados Unidos demonstram que o preconceito tem mudado suas formas de expressão, buscando atender à norma do igualitarismo, mas não há evidências de que ele tenha de fato desaparecido.

Pettigrew e Meertens (1995), por exemplo, verificaram que o preconceito racial na Europa apresenta-se sob duas formas: o flagrante e o sutil. 0 racismo flagrante é a forma mais tradicional de expressão do preconceito, sendo ela mais direta, quente e aberta. Allport (1954) falava desse tipo de expressão. Já o racismo sutil é a forma mais contemporânea de discriminação, é discreta, fria, indireta e, dessa forma, além de preservar a expressão do preconceito atende à norma da não discriminação, em que as pessoas consideram ina- ceitável ser preconceituoso e temem ser mal vistas por apresentarem tal comportamento.

Os estudiosos do preconceito étnico e racial no Brasil e em várias partes do mundo (Camino, Silva, Machado \& Pereira, 2001; Lima, Pinheiro, Pacheco, Lima \& Vala, 2006; Moscovici \& Pérez, 1999; Pettigrew \& Meertens, 1995; Pereira, Torres \& Almeida, 2001) encontraram evidências de que expressões mais sutis desse fenômeno estão desenvolvendo subprodutos que atendem à necessidade de perpetuação dos comportamentos discriminatórios ao mesmo tempo em que preservam a imagem igualitária dos atores sociais.

De acordo com Leyens et al. (2000), um desses subprodutos é o processo chamado de infra-humanização. Leyens et al. (2003, p.705) afirmam que"do ponto de vista etimológico, infra-humanização expressa o sentido de que alguns humanos são considerados menos humanos do que outros ${ }^{\prime 4}$.

A perspectiva da infra-humanização está baseada no essencialismo psicológico, em que as pessoas são dotadas de essências que as determinam como "boas" ou "más", "normais" ou "divergentes". A partir dessa essencialização, as pessoas, principalmente aquelas referentes aos exogrupos, serão dotadas de características que, de alguma forma, as transformem em "menos humanas". Até o momento, essa perspectiva tem sido utilizada para estudar o preconceito racial (Leyens et al. 2001, 2003; Lima \& Vala, 2005). No entanto a questão que norteia o desenvolvimento deste trabalho refere-se ao grupo de homossexuais: será que o processo de infra-humanização também se fará presente quando temos como grupo-alvo do preconceito essa minoria social?

\section{O preconceito por orientação sexual no Brasil}

Na área da Psicologia Social, o preconceito racial e étnico tem sido um dos temas mais ativamente pesquisados. No entanto o preconceito contra homossexuais não tem recebido a mesma atenção. Um levantamento feito na SciELO (Scientific Eletronic Library On-Line), no dia 30 de abril de 2006, usando a palavra-chave "preconceito contra homossexuais", resultou 
apenas no trabalho de Lacerda, Pereira e Camino (2002). Essa falta de atenção da Psicologia Social sobre o tema opõe-se ao grande interesse que a sociedade moderna tem revelado a respeito das questões relacionadas à homossexualidade de forma geral. Esse interesse é perceptível tanto nos movimentos que lutam pelos direitos dos homossexuais, tal como a parada gay, que cresce em número de participantes todos os anos, no Brasil e no mundo, como em programas sociais que têm como objetivo diminuir o preconceito. O programa "Brasil sem Homofobia", lançado em 2004, é uma resposta aos altos índices de discriminação contra o grupo. Ele atende a casos que vão desde a exclusão social até a atos violentos contra essa minoria.

Os resultados da pesquisa "Juventudes e Sexualidade" (Castro, Abramovay \& Silva, 2004), realizada pela Organização das Nações Unidas para a Educação, a Ciência e a Cultura (Unesco) e lançada no dia 8 de março de 2004, apontam a necessidade de a Psicologia Social se dedicar mais ao estudo do preconceito contra os homossexuais. Realizada em 14 capitais brasileiras, essa pesquisa revelou que $25 \%$ dos estudantes pesquisados não gostariam de ter um colega de classe homossexual (resposta majoritariamente emitida por estudantes do sexo masculino). As capitais que obtiveram maior índice de rejeição foram Fortaleza, Recife e Goiânia. Ainda referente a essa pesquisa, foi questionado se consideravam a homossexualidade uma doença. As respostas obtidas revelaram que 18\% de goianienses e 11,9\% de porto-alegrenses acreditam que a homossexualidade é uma doença, configurando esses percentuais como os maiores índices do país. Essa pesquisa também constatou que 33\% dos pais de alunos goianos não gostariam que os filhos tivessem colegas de sala homossexuais.

Os dados acima apontam a presença de um esquema social discriminatório contra o homossexual na sociedade brasileira diferente do preconceito racial na sua forma de expressão. Os poucos trabalhos sobre o preconceito e a discriminação contra homossexuais realizados no Brasil (Falcão, 2004; Lacerda et al., 2002; Pereira, 2004) apresentam resultados que apontam a expressão flagrante do preconceito contra os homossexuais, ou seja, mais aberta e mais direta, menos preocupada em atender às normas do igualitarismo.

Spencer (1999) defende que a análise da história da sexualidade evidencia o preconceito contra os homossexuais como uma construção sócio-histórica. A instituição Igreja Católica modelou essa construção e ainda controla e direciona, de alguma forma, como os homossexuais são encarados pela sociedade. Assim, o estudo de Pereira (2004) buscou avaliar como as diferentes explicações para a homossexualidade e as características sociográficas, principalmente a religião dos participantes envolvidos em seu estudo, ancoram o preconceito contra os homossexuais. As explicações utilizadas no estudo são os cinco tipos constatados por Lacerda et al. (2002): explicações biológicas, psicológicas, religiosas, ético-morais e explicações psicossociais. Partiu-se do suposto de que as explicações da homossexualidade funcionam como um sistema de justificação normativo, que oferece aos participantes do estudo a possibilidade de discriminar e expressar atitudes hostis ao grupo de homossexuais, sem "ameaçar a percepção de que eles estariam executando ações para o bem-estar social, pois estaria a serviço de Deus quem é'Bom' por natureza" (Pereira, 2004, p.107).

A análise dos dados do estudo de Pereira (2004) confirma a hipótese geral de Lacerda et al. (2002) de que as explicações sobre a homossexualidade se dividem em cinco tipos, conforme exposto anteriormente. A explicação biológica estaria baseada na idéia de que a homossexualidade seria uma doença provocada por distúrbios de natureza fisiológica, hormonal ou gestacional. A explicação ético-moral representaria a crença de que a homossexualidade está relacionada com a ausência de respeito, de caráter e de valores morais do indivíduo. Já a explicação religiosa aponta o homossexual como uma pessoa que não segue a palavra de Deus, que não tem força espiritual e religiosidade para resistir às tentações. A explicação de ordem psicossocial organiza as crenças de que a homossexualidade não é doença e deve ser compreendida na sua totalidade, pois trata da forma distinta pela qual cada um vive sua sexualidade, que é parte da identidade do sujeito. Por último, temos a explicação psicológica, constituída pela crença de que a homossexualidade é resultado de traumas experienciados na primeira infância.

Os resultados do estudo de Pereira (2004) indicaram que o grupo de preconceituosos sutis tende a explicar a homossexualidade com base em causas psicossociais e é formado por estudantes do sexo 
feminino, católicas, mais velhas e com mais tempo de seminário (os participantes eram estudantes de teologia). Já o grupo de preconceituosos flagrantes atribui explicações ético-morais e religiosas, e tende a discordar das explicações psicossociais e constitui-se de estudantes evangélicos, do sexo masculino, mais jovens e com mais tempo de seminário.

O trabalho de Falcão (2004) tinha como objetivo investigar se havia relação entre as explicações que as pessoas davam para a homossexualidade e as atitudes dessas pessoas acerca da adoção de crianças por homossexuais. Os resultados demonstraram que a relação existe e se diferencia conforme as crenças quanto às causas da homossexualidade. As pessoas que dão explicações psicossociais para a homossexualidade, e acreditam que se deva tentar compreendê-la em sua totalidade, são favoráveis à adoção de crianças por homossexuais. Já as pessoas que consideram a falta de caráter, de respeito e de valores morais como causas da homossexualidade são contrárias à adoção de crianças por homossexuais, além de terem sido classificadas como preconceituosas flagrantes, ou seja, acreditam que a explicação da condição do homossexual por si só justifica as atitudes discriminatórias dirigidas ao grupo. Nessa pesquisa também ficou evidenciado que, de maneira geral, as mulheres são mais tolerantes tanto com a homossexualidade em geral como com a legalização da união entre pessoas do mesmo sexo.

Este estudo trabalha com a concepção da homossexualidade como construção social e, como tal, está baseada nas relações sociais de poder que configuram a estrutura do preconceito em determinada sociedade. Entende-se essa construção social como resultado de processos sociocognitivos e, por isso, ligados à relação estabelecida entre indivíduo e sociedade, na qual a influência é recíproca, ou seja, não há uma relação de causalidade, mas sim uma relação de mão-dupla, de influência mútua. Com base nessa concepção, acreditamos que mudanças sociais, econômicas e políticas produzam modificações comportamentais que atendem às novas condições ambientais ao mesmo tempo em que essas condições são retroalimentadas pelas modificações produzidas nos indivíduos por elas afetados. Essa concepção influenciou 478 a utilização de uma medida de preconceito sutil neste estudo, no caso a infra-humanização, visto que se apresenta como uma alternativa à perpetuação do preconceito numa sociedade em que as normas anti-racistas estão presentes.

\section{Infra-humanização e preconceito}

Para compreender o processo de infra-humanização é necessário desenvolver o entendimento sobre o essencialismo psicológico e como ele atua na categorização social e, conseqüentemente, no fenômeno do preconceito.

O essencialismo psicológico caracteriza-se pela crença de que objetos naturais e sociais são detentores de essências ou naturezas fundamentais que fazem deles o que eles são. Como tal, constitui uma forma de pensamento que auxilia o processo de categorização e a formação de estereótipos.

Conforme Lima et al. (2006), nessa forma de pensamento, características visíveis e superficiais seriam preditoras de características profundas e invisíveis do objeto. Dessa maneira, podemos dizer que se referem mais à forma de como o objeto é percebido do que à sua real natureza. O essencialismo psicológico apóia-se na necessidade cognitiva do indivíduo de transcender a informação dada a fim de melhor compreender dado objeto ou fenômeno social (Allport, 1954).

A atuação do essencialismo psicológico na categorização social fornece pré-julgamentos que delinearão nossos comportamentos nas nossas relações. Essa tendência em extrair do objeto elementos outros a partir de alguns percebidos contribui na elaboração dos conteúdos que irão determinar nossos preconceitos. A essencialização das diferenças poderá conduzir a sua hierarquização, caracterizando o preconceito e infra-humanizando objetos naturais e sociais.

O fato de a essencialização estar presente entre os grupos, leva-nos a crer que ela é base para a formação de categorias e de seus respectivos grupos sociais, fornecendo, assim, argumentos para a diferenciação entre eles. Para Leyens et al. (2000), na perspectiva do essencialismo psicológico, as pessoas tendem a explicar as diferenças entre os grupos atribuindo a eles diferentes essências, acreditando, assim, que elas podem definir a natureza dos grupos. E esse fato independe do status do 
grupo. Discursos de grupos dominantes ou de dominados geralmente recorrem a uma visão essencialista, seja para legitimar sua superioridade ou para justificar sua inferioridade e, assim, partir para reivindicações (Haslam \& Levy, 2006).

O processo de infra-humanização seria resultado de um essencialismo que nega a membros de outros grupos determinadas características tipicamente humanas, que seriam constituintes da "essência humana". Estudos sobre o tema revelaram como características unicamente humanas os valores (Struch \& Schwartz, 1989), a cultura (Moscovici \& Pérez, 1999), a linguagem, a inteligência e a capacidade de expressar sentimentos (Leyens et al., 2000).

Em Psicologia Social, a infra-humanização é investigada basicamente a partir de três indicadores: a negação da capacidade do exogrupo de adotar valores tipicamente humanos; a desculturalização do exogrupo, caracterizando-o por meio de traços de natureza em oposição aos traços de cultura; e a menor atribuição de sentimentos para o exogrupo.

Característica fundamental do processo de infra-humanização é a não diferenciação dos grupos a partir da valência positiva ou negativa. No que diz respeito a emoções, traços e valores, a diferenciação intergrupal ocorre não pela derrogação do outro grupo a partir do uso das valências negativas em relação às características atribuídas ao exogrupo, mas sim pela diferenciação em relação às características consideradas mais ou menos humanas. Justamente a partir dessa concepção fundamental, o processo de infra-humanização apresenta-se como um fenômeno relacionado às novas formas de expressão do preconceito, pois todas elas têm como característica principal a sutileza na sua expressão, evitando a derrogação do outro grupo e valorizando o próprio grupo, preservando a diferenciação intergrupal, mas sem ferir as normas do igualitarismo. Em outras palavras, essa diferenciação intergrupal ocorre não porque o exogrupo é considerado "pior", mas porque o endogrupo é considerado "melhor" que o exogrupo. No caso da infra-humanização, o endogrupo é considerado "melhor" porque possui mais características humanas, independendo da valência que essas características possuem.

Struch e Schwartz (1989) foram os primeiros a estudar a concepção de que certos processos psico- lógicos são exclusivamente humanos e, sendo assim, diferenciam seres humanos e animais. Para esses autores, a infra-humanização pode ocorrer no âmbito da diferenciação de valores e, quando é assim, quanto maior o nível de identificação com o grupo de pertença e a percepção de que o exogrupo se diferencia na adoção de valores, maior a sua infra-humanização. Isso ocorre, também, no nível da capacidade de expressar valores considerados humanos, tais como compaixão, solidariedade, educação. Nesse ponto, aproxima-se da diferenciação em nível de traços culturais e sentimentos entre as pessoas e/ou entre os grupos.

Leyens et al. $(2001,2003)$ realizaram vários estudos para investigar o papel da atribuição de emoções primárias e sentimentos na infra-humanização dos exogrupos. As emoções primárias são definidas por esses autores como emoções expressas tanto por animais quanto por seres humanos. Caracterizam-se por um rápido início, uma curta duração, além de aparecerem muito cedo na vida das pessoas e dos animais (Ekman, 1992; Sroufe, 1979). Alguns exemplos de emoções primárias são raiva, surpresa, medo, alegria, tristeza etc. Estão mais relacionadas a emoções natas, podendo ser pouco influenciadas pela nossa cultura. Já os sentimentos ou as emoções secundárias resultam de uma associação de novos rótulos com vários aspectos das interações sociais (Kemper, 1987). Freqüentemente, elas são uma composição das emoções primárias e caracterizam-se por ter uma longa duração, ser menos intensas, envolver mais moralidade, cognição e sensibilidade. Além disso, são menos visíveis e surgem mais tarde na vida das pessoas. Enfim, são resultantes do processo de socialização do homem. Alguns exemplos de emoções secundárias são mágoa, desprezo, felicidade, vaidade, admiração etc.

Leyens et al. (2001) verificaram que a diferenciação intergrupal ocorre mais a partir da não atribuição ao exogrupo de emoções secundárias, não havendo diferenças no nível das emoções primárias nem em relação às valências das emoções e dos sentimentos.

Em se tratando de cultura, faz-se necessário que os estudos de Moscovici e Pérez (1999) sobre a infra-humanização como essencialização das diferenças em termos de desculturalização sejam compreendidos. Essa teoria envolve a compreensão do que são considerados "traços naturais" e "traços culturais", que equivalem 
respectivamente às chamadas emoções primárias e sentimentos ou emoções secundárias, da teoria de Leyens et al. (2001), que consideram, conforme visto anteriormente, a infra-humanização como essencialização das diferenças no nível das emoções. Os primeiros, traços naturais, são definidos por Moscovici e Pérez (1997) como características que podem ser atribuídas tanto aos seres humanos como aos animais, tais como: intuitivo, livre, espontâneo, selvagem, impulsivo, entre outras. Já os "traços culturais" são aqueles típicos do ser humano, tais como criativo, leal, fiel, cooperativo, amigável, etc., também resultantes do processo de socialização. Vale ressaltar que os autores, para conceber tal teoria, utilizaram um estudo sobre as representações sociais dos ciganos na Espanha. Os resultados desse estudo demonstraram que, quando os ciganos resistem à adoção da cultura dominante, são descritos pelos não-ciganos com mais adjetivos baseados em traços naturais do que quando se tornam semelhantes aos indivíduos da cultura dominante, nesse caso, os espanhóis.

Nosso estudo será baseado nos estudos de Moscovici e Pérez (1999), propondo investigar a diferenciação no nível de traços culturais dos heterossexuais e dos homossexuais.

Alguns fatores fundamentais para a realização desse estudo foram considerados. Primeiramente, consideramos recentes estudos sobre a expressão do racismo no Brasil (Martinez \& Camino, 2000; Venturi \& Paulino, 1995) que revelam que as pessoas no nosso país têm uma clara consciência da existência de discriminação racial nas relações sociais, mas não se sentem individualmente responsáveis por essa situação. Apoiando-nos nesses estudos, optamos por utilizar o deslocamento das respostas dos participantes, questionando a opinião deles sobre como eles acham que a "sociedade brasileira" percebe o homossexual. Posteriormente, estabelecemos que, conforme resultados dos estudos recentes sobre a expressão do preconceito nas sociedades ocidentais (Vala et al., 1999), deveríamos utilizar uma teoria que nos oferecesse condições de investigar novas formas de expressão do preconceito, já que há uma concordância entre os teóricos estudiosos do fenômeno do preconceito (Gaertner \& Dovídio, 1986; Pettigrew \& Meertens, 1995; Vala et al., 1998, 1999) de que ele está assumindo formas de expressão mais sutis 480 e menos flagrantes, buscando atender, assim, às normas antipreconceituosas vigentes em nossa sociedade. Introduzimos aqui o indicador de infra-humanização a fim de avaliarmos se a expressão do preconceito contra os homossexuais na nossa sociedade apresenta componentes da infra-humanização.

As hipóteses deste trabalho são: - possivelmente serão atribuídos mais traços culturais para o grupo dos heterossexuais do que para o de homossexuais; - possivelmente não haverá diferença significativa na atribuição de traços naturais entre o grupo de homossexuais e o grupo de heterossexuais.

Neste estudo, portanto, procurou-se entender o papel desempenhado pela orientação sexual (homossexuais vs. heterossexuais) na atribuição diferenciada de traços naturais e culturais (infra-humanização) aos grupos de homossexuais e de heterossexuais. Esclarecemos que a realização deste trabalho foi aprovada pelo Comitê de Ética em Pesquisa da Universidade Católica de Goiás (Protocolo 0031/03) em 26/03/2003.

\section{Método}

\section{Participantes}

A amostra deste estudo foi intencionalmente composta por 135 estudantes da área de recursos humanos que cursavam pós-graduação lato sensu nessa mesma área, graduados em Psicologia e em Administração de Empresas que já atuavam na área ou planejavam atuar. A escolha dessa amostra teve como objetivo investigar a percepção de pessoas envolvidas ou que pretendem envolver-se com o processo seletivo nas organizações, visto que a exclusão profissional é um ponto relevante na situação de exclusão social a que o grupo de homossexuais está sujeito. Participaram estudantes de três diferentes instituições de ensino privado na cidade de Goiânia, Goiás. A maioria dos participantes é do sexo feminino (87\%). A idade média (M) desses profissionais é igual a 30 anos (desvio-padrão (DP) $=7,2$ anos).

\section{Instrumentos}

O instrumento desenvolvido para este estudo foi baseado no trabalho de Lima (2002) e validado em um estudo-piloto realizado em Goiânia. 
Utilizamos a versão adaptada por Lima (2002), validada no nosso primeiro estudo, da Escala de traços naturais e culturais utilizada nos estudos de Moscovici e Pérez (1999) para avaliar o preconceito contra os ciganos na Espanha. Foram escolhidos os 24 adjetivos, de um total de 40, mais pertinentes ao tema investigado. Conservamos o equilíbrio e a valência na definição dos traços, sendo 12 traços naturais, 12 culturais, 12 positivos e 12 negativos. Aos participantes era solicitado que indicassem o grau em que, na opinião deles, a sociedade brasileira utiliza os adjetivos da escala para caracterizar os homossexuais e os heterossexuais. O grau para avaliar os adjetivos variava de zero (nada característico) a quatro (totalmente característico).

Logo abaixo da escala estavam as perguntas sobre os dados sociográficos (idade, gênero e curso). A penúltima questão estava relacionada à forma como o participante acredita que a sociedade brasileira vê o homossexual. A avaliação poderia variar de um (muito negativa) a sete (muito positiva). Para finalizar o questionário, a última questão perguntava ao participante se ele concorda com a opinião da "sociedade brasileira". A sua concordância poderia variar de um (discordo totalmente) a sete (concordo totalmente). Esclarecemos ainda que cada participante respondeu apenas a um tipo de questionário.

\section{Resultados e Discussão}

A análise preliminar dos dados buscou não só averiguar a porcentagem de casos com valores omissos no conjunto de todas as variáveis, como também detectar possíveis erros de tabulação (Kinnear \& Gray, 1999). Procedeu-se, posteriormente, ao estudo exploratório dos dados, de forma a avaliarmos os pressupostos essenciais da análise estatística univariada e multivariada: (1) normalidade da distribuição em cada variável, (2) presença de casos outliers univariados e multivariados, (3) multicolinearidade e singularidade (Kinnear \& Gray, 1999; Tabachnick \& Fidel, 1996).

\section{Orientação sexual, os traços naturais e os culturais}

Primeiramente, investigou-se a estrutura da escala de traços naturais e culturais (Lima, 2002) por meio da realização de uma análise fatorial. Essa técnica objetiva descobrir e analisar a estrutura de um conjunto de variáveis inter-relacionadas de modo a construir uma variável composta por diversos itens (Maroco, 2003).

Inicialmente, verificou-se a adequação da amostra (Tabachnick \& Fidel, 1996) para o uso desse teste estatístico. $O$ coeficiente do teste de esfericidade de Bartlett foi igual a 1,073,544 (276) $(p<0,001)$. A adequação da amostra, verificada pelo teste de Kaiser-Meyer-Olkin, indicou uma adequação razoável dos dados para a análise fatorial $(\mathrm{KMO}=0,772)$. Em conjunto, esses resultados indicam que o uso da análise fatorial seria adequado para essa amostra.

Com a indicação de estudos anteriores (Lima, 2002; Moscovici \& Peréz, 1999), primeiramente se efetuaram extrações com quatro fatores, aplicando-se o método mais utilizado, chamado Fatores Principais (Kinnear \& Gray, 1999). Os resultados da análise fatorial indicaram a existência de dois fatores que não se agruparam conforme a divisão estabelecida em traços naturais e traços culturais (Lima, 2002; Moscovici \& Peréz, 1999). Com base na análise dos itens, constatou-se que, de fato, os itens se agruparam de acordo com suas respectivas valências: positiva ou negativa. Quando analisadas as avaliações para os dois grupos, homossexuais e heterossexuais, separadamente, a estrutura permaneceu muito parecida. Exceção foi o item supersticioso: para os homossexuais, ficou no grupo de avaliação de valência positiva; para os heterossexuais, negativa. Quanto à fidedignidade, os índices foram altos (alfas de Cronbach entre 0,82 e 0,88), o que nos permitiu verificar que a escala utilizada mediu o fenômeno a que se propôs, possibilitando assim uma maior precisão na análise dos nossos resultados.

\section{Análise estatística do teste das hipóteses}

Como a análise fatorial ordenou a escala em dois fatores (positivos e negativos), decidiu-se realizar duas ANOVAs. Uma para comparar o efeito da variável independente em relação à atribuição de características positivas entre os homossexuais e os heterossexuais; outra para verificar o efeito da variável independente na variável dependente em relação à atribuição de características negativas para os dois grupos. A ANOVA tem como objetivo comparar duas ou mais médias a 
fim de verificar a existência de diferenças estatisticamente significativas entre elas (Maroco, 2003).

\section{Avaliação positiva}

A análise descritiva (Tabela 1) dos grupos apresenta as diferenças das avaliações entre os grupos. O Paired-Samples T Test mostrou o efeito significativo das avaliações de homossexuais e heteressexuais relativas à atribuição de características positivas feita pelos participantes em função da orientação sexual dos grupos ( $\mathrm{t}=-3,726 ; p=0,05)$. Assim, aos heterossexuais foram atribuídas mais características positivas do que aos homossexuais.

\section{Avaliação negativa}

A análise descritiva (Tabela 2) dos grupos apresenta as diferenças das avaliações entre eles. 0 Paired-Samples T Test não revelou efeito significativo das avaliações de homossexuais e heterossexuais relativas à atribuição de características negativas, indicando que a diferença entre as avaliações negativas dos dois grupos não foi estatisticamente significativa.

Os resultados encontrados neste trabalho mostram a ausência do fenômeno da infra-humanização na atribuição dos traços aos grupos de homossexuais e de heterossexuais. Conforme foi dito, a divisão estabelecida pela análise fatorial mostrou a existência de dois fatores relacionados às valências dos traços: positivos e negativos. Provavelmente a suposição de Lima (2002) sobre a não validade dos indicadores de essencialização das diferenças culturais (traços naturais e culturais) em uma sociedade como a brasileira encontra confirmação nos resultados deste estudo.

O trabalho de Lima (2002) teve como objetivo investigar se o processo de infra-humanização está presente na discriminação racial, numa perspectiva que analisa o racismo como essencialização da cultura minoritária. Além disso, buscou verificar o efeito das normas sociais na infra-humanização e o papel do branqueamento como fenômeno mediador do processo discriminatório. Para consecução do seu objetivo, o autor utilizou um conjunto de indicadores para analisar a infra-humanização (Leyens et al., 2001; Moscovici \& Pérez, 1999). Os resultados apontam que o efeito desses indicadores foi mediado pelo branqueamento, ou seja, os negros bem-sucedidos eram vistos como mais brancos do que os negros fracassados. Portanto o processo de branqueamento tornou-se a mediação necessária para que o exogrupo atribuísse mais sentimentos e traços culturais aos negros bem-sucedidos.

Lima (2002) conclui, então, que esses indicadores de infra-humanização, eficazes nos estudos sobre preconceito na Europa, podem não ser tão bons no nosso contexto, em que negros e brancos são, ao menos no âmbito formal, integrados culturalmente. Em relação ao preconceito por orientação sexual, apesar de não terem sido eficazes nesta pesquisa, outras investigações são necessárias para a demonstração de sua ineficácia no estudo desse tema.

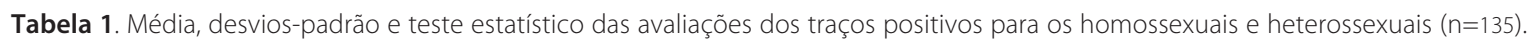

\begin{tabular}{|c|c|c|c|c|c|}
\hline & \multicolumn{2}{|c|}{ Avaliação } & \multicolumn{3}{|c|}{ Teste estatístico } \\
\hline & Homossexual & Heterossexual & $t$ & gl & $p<$ \\
\hline Traços positivos & $\begin{array}{c}2,0 \\
(0,66)\end{array}$ & $\begin{array}{c}2,26 \\
(0,70)\end{array}$ & $-3,726$ & 134 & 0,01 \\
\hline
\end{tabular}

Tabela 2. Média, desvios-padrão e teste estatístico das avaliações dos traços negativos para os homossexuais e heterossexuais ( $\mathrm{n}=135$ ).

\begin{tabular}{|c|c|c|c|c|c|}
\hline & \multicolumn{2}{|c|}{ Avaliação } & \multicolumn{3}{|c|}{ Teste estatístico } \\
\hline & Homossexual & Heterossexual & $t$ & $g l$ & $p<$ \\
\hline Traços negativos & $\begin{array}{c}1,8 \\
(0,76)\end{array}$ & $\begin{array}{c}1,8 \\
(0,68)\end{array}$ &,- 626 & 134 &,- 532 \\
\hline
\end{tabular}


No entanto, embora a infra-humanização não esteja presente em nossos resultados, isso não significa que processos discriminatórios estejam totalmente ausentes. A atribuição de características positivas aos heterossexuais foi significativamente superior à atribuição feita para os homossexuais. Já a diferença de atribuição de traços negativos não foi estatisticamente significativa para os dois grupos. Esses resultados corroboram os resultados de outros autores (Camino et al., 2001; Dovídio, Mann \& Gaertner, 1989; Vala et al., $1998,1999)$ que, buscando investigar as formas mais sutis do preconceito nas sociedades ocidentais, verificaram que atualmente uma maior atribuição de traços positivos para o próprio grupo sobrepõe-se à atribuição de traços negativos para o outro grupo.

Vala et al. (1998), por exemplo, investigaram o racismo em Portugal a partir de uma medida de preconceito sutil: a não-atribuição de características positivas aos negros. Os resultados do estudo demonstraram uma diferença significativa em relação à avaliação positiva, pois os portugueses atribuíram mais traços positivos para o próprio grupo do que para qualificar os imigrantes negros. Apesar de os negros terem sido avaliados com menos traços positivos, a diferença de atribuição de traços negativos não foi significativa. A medida de preconceito sutil foi eficaz nessa investigação, corroborando com os mais recentes estudos sobre racismo na Europa.

Os resultados desse estudo também são coerentes com os pressupostos das novas teorias sobre o fenômeno do preconceito (Kinder \& Sears, 1981; Pettigrew \& Meertens, 1995), que postulam que, após a formulação de leis que proíbem as práticas discriminatórias, o preconceito adquiriu formas mais sutis de expressão.

Finalmente, os resultados das duas últimas questões do questionário revelam um aspecto interessante sobre a manifestação do preconceito no Brasil, igualmente já verificado nos estudos de Camino et al. (2001), Pereira et al., (2003a) e Venturi e Paulino (1995). Tomados em conjunto, esses estudos resultaram na constatação de que"o discurso ideológico que organiza as relações raciais no Brasil descreve uma dissociação cognitiva cuja característica central é o fato de as pessoas negarem que são preconceituosas, atribuindo a responsabilidade do preconceito a uma abstração: a sociedade brasileira" (Pereira et al., 2003b, p.99).

Os nossos resultados também corroboram a conclusão acima citada. As avaliações dos participantes em relação à forma como pensam que a sociedade brasileira vê o homossexual mostram que eles acreditam que a percepção da sociedade brasileira sobre o homossexual é mais negativa $(M=2,52 ; D P=1,27)$. No entanto, quando perguntados se eles, individualmente, concordam com essa avaliação negativa, os participantes majoritariamente não concordam ( $M=2,84$; $\mathrm{DP}=1,97)$.

O estudo de Camino et al. (2001) tinha como objetivo demonstrar a dissociação cognitiva que permite que, no Brasil, as pessoas concordem com a existência do preconceito ao mesmo tempo em que negam ser preconceituosas. A maioria dos participantes (82\%) escolheu a alternativa que atribui a responsabilidade da existência do preconceito no Brasil a uma abstração, visto que os participantes individualmente não se consideram preconceituosos.

A atribuição do preconceito a uma abstração - a "sociedade brasileira" - ao mesmo tempo em que justifica a realidade das minorias discriminadas, desresponsabiliza as pessoas pela situação desses grupos alvos da marginalização e da exclusão social. Dessa forma, o brasileiro corresponde à norma do politicamente correto e à crença da democracia racial e ainda justifica seus atos de discriminação que, conforme Pereira et al., (2003ab) podem ocorrer em situações em que o discurso justificador esteja presente.

\section{Considerações Finais}

O objetivo deste estudo foi investigar o preconceito contra os homossexuais e suas novas formas de expressão. Partimos do suposto que o preconceito contra esse grupo minoritário poderia ser investigado com base nas idéias, defendidas por Moscovici e Pérez (1999) e Lima (2002), de que a expressão do preconceito na atualidade pode apresentar componentes de infra-humanização.

A infra-humanização como processo de essencialização das diferenças foi avaliada, neste estudo, a partir da análise de uma menor atribuição de traços 
culturais aos homossexuais feita por estudantes da área de recursos humanos. As nossas hipóteses baseavam-se nos estudos mais recentes do preconceito racial (Lima, 2002; Camino et al., 2001; Leyens et al., 2000), que revelam que as mudanças de expressão do preconceito ocorrem devido às normas sociais vigentes, que coíbem comportamentos discriminatórios. Apesar de os resultados não indicarem a presença dos componentes de infra-humanização no preconceito contra os homossexuais, eles apontaram para uma diferenciação significativa na atribuição de características positivas entre os grupos.

Os resultados deste estudo apontam o preconceito dirigido ao grupo de homossexuais como sutil, diferentemente de outras pesquisas na área, que indicavam a existência de um maior percentual de preconceituosos flagrantes (Lacerda et al., 2002; Falcão, 2004; Pereira, 2004). O estudo de Falcão (2004), discutido anteriormente, relacionava as explicações sobre a homossexualidade à expressão do preconceito. Os resultados desse trabalho mostram que $77 \%$ dos estudantes foram classificados como preconceituosos flagrantes e sutis e 44\% apresentavam a expressão flagrante do preconceito.

Uma hipótese explicativa sobre a diferença nos resultados do estudo de Falcão (2004) com o presente estudo estrutura-se na questão do público e do privado, já que a adoção refere-se à esfera privada e aos vários mitos que o assunto envolve, tal como a idéia de que uma criança criada em um ambiente homossexual acumulará traumas psicológicos e sociais que irão refletir no desenvolvimento de sua personalidade. Além disso, esse mito serviria de justificativa para que as pessoas agissem de forma mais flagrante, sem preocupação com a norma antidiscriminatória.

Já o estudo de Pereira (2004) teve como amostra estudantes de Teologia, o que, de fato, colabora para expressões mais flagrantes do preconceito, pois, conforme Herek (2002), a retórica religiosa é extremamente conservadora e opõe-se aos direitos gays, condenando tanto a homossexualidade masculina quanto a feminina.

Há ainda de se considerar o fato de nossa amostra ter sido formada, em sua maioria (87\%), por mulheres com idade média de 30 anos, com escolaridade superior completa. Segundo Herek (2002), vários estudos comprovam que o homem heterossexual e a mulher heterossexual reagem diferentemente à homossexualidade. O homem heterossexual geralmente expressa maiores níveis de preconceito sexual do que a mulher heterossexual. Essa diferença é mais significativa na atitude dos heterossexuais em relação aos homossexuais masculinos. A replicação deste estudo numa amostra masculina poderá trazer maiores informações para a confirmação da diferença na expressão de preconceito na nossa sociedade a partir do gênero e possibilitará identificar a influência do sexo dos participantes no preconceito contra homossexuais.

O debate sobre a situação do homossexual no mercado de trabalho é muito mais amplo do que este estudo se propõe a investigar. A análise da visão dos estudantes da área de Recursos Humanos sobre a homossexualidade e o preconceito implica somente um aspecto particular da situação profissional do homossexual, ao mesmo tempo em que identifica a questão da orientação sexual como uma desvantagem para o grupo de homossexuais na competição pelas vagas no mercado, visto que a análise dos profissionais de recursos humanos será influenciada por um favoritismo pelo grupo majoritário: os heterossexuais.

Algumas pesquisas no Brasil (Falcão, 2004; Green, 1999; Lacerda et al., 2002; Pereira, 2004; Rios, 2002) apontam resultados que indicam a existência do preconceito e da discriminação na vida desse grupo minoritário. As atitudes negativas dos heterossexuais para com o grupo de homossexuais são experienciadas, provavelmente, de diferentes formas, em graus distintos, mas a persistência do fenômeno incita respostas sobre as conseqüências dessas atitudes no cotidiano dos homossexuais.

O governo brasileiro lançou, no dia 25 de maio de 2004, o programa"Brasil sem Homofobia". O objetivo do programa é desenvolver ações que previnam a violência contra as minorias sexuais. Dados oficiais do governo brasileiro revelam que, de 1963 a 2001, tivemos 2.092 homossexuais assassinados no país. O programa tem como prioridade implementar ações que consigam diminuir a discriminação contra essa minoria.

A breve exposição acima realizada sobre a homofobia e as ações que mobilizam algumas áreas da nossa sociedade tem aqui o objetivo de ressaltar a relevância do tema proposto no presente trabalho. 
De acordo com o que foi dito, apesar de toda essa movimentação social, as pesquisas científicas na área são escassas. Há a necessidade de investigarmos a configuração do preconceito e da discriminação contra o homossexual em nossa sociedade para que possamos compreender os mecanismos que promovem essa situação e, assim, estarmos aptos a propor intervenções que venham diminuir, ou, preferencialmente, eliminar os conflitos intergrupais, favorecendo o bem-estar social.

\section{Referências}

Allport, G. (1954). The nature of prejudice. Cambridge: Addison-Wesley.

Camino, L., Silva, P., Machado, A., \& Pereira C. (2001). A face oculta do preconceito no Brasil: uma análise psicossociológica. Revista Psicologia Política, 1 (1), 13-36.

Castro, M. G., Abramovay, M., \& Silva, L. B. (2004). Juventudes e sexualidades. Brasília: Unesco.

Dovídio, J. F., Mann, J. A., \& Gaertner, S. L. (1989). Resistence to affirmative action: the implications of aversive racism. In F. A. Blanchard \& F. J. Crosby (Orgs.), Affirmative action in perspective (pp.83-102). New York: Springer-Verlag.

Ekman, P. (1992). An argument for basic emotions. Cognition and Emotion, 6 (2), 169-200.

Falcão, L. C. (2004). Adoção de crianças por homossexuais: crenças e formas de preconceito. Dissertação de mestrado não-publicada, Universidade Católica de Goiás, Goiânia.

Gaertner, S. L., \& Dovidio, J. F. (1986). The aversive form of racism. In J. F. Dovidio \& S.L. Gaertner (Eds.), Prejudice, discrimination, and racism: theory and research (pp.61-89). Orlando, FL: Academic Press.

Green, J. N. (1999). A Homossexualidade masculina no Brasil do século XX. São Paulo: Unesp.

Haslam, N., \& Levy, S. R. (2006). Essentialist beliefs about homosexuality: structure and implications for prejudice. Personality and Social Psychology Bulletin, 32 (4), 471-485.

Herek, G. M. (2002). Gender gaps in public opinion about lesbians and gay men. Public Opinion Quarterly, 66 (1), 40-66.

Kemper, T. D. (1987). How many emotions are there? Wedding the social and automatic componentes. American Journal of Sociology, 93 (2), 263-289.

Kinder, D. R., \& Sears, D. O. (1981). Prejudice and politics: symbolic racism versus racial threats to the good life. Journal of Personality and Social Psychology, 40 (3), 414-431.

Kinnear, P. R., \& Gray, C. D. (1999). SPSS for Windows made simple (3rd ed.). Hove, East Sussex: Psychology Press.

Lacerda, M., Pereira, C., \& Camino, L. (2002). Um estudo sobre as formas de preconceito contra homosexuais na perspectiva das representações sociais. Psicologia Reflexão e Crítica, 15 (1), 165-178.

Leyens, J., Paladino, P., Rodriguez-Torres, R., Vaes, J., Demoulin, S., Rodriguez-Perez, A., \& Gaunt, R. (2000). The emotional side of prejudice: the attribution of secondary emotions to ingroups and outgroups. Personality and Social Psychology Review, 4 (2), 186-197.

Leyens, J. Ph., Rodriguez-Perez, A., Rodriguez-Torres, R., Gaunt, R., Paladino, P., Vaes, J., \& Demoulin, S. (2001). Psychological essentialism and the differential attribution of uniquely human emotions to ingroups and outgroups. European Journal of Social Psychology, 31 (4), 395-411.

Leyens, J. Ph., Cortes, B. P., Demoulin, S., Dovidio, J., Fiske, S. T., Gaunt, R. (2003). Emotional prejudice, essentialism, and nationalism. European Journal of Social Psychology, 33 (6), 703-717.

Lima, M. E. (2002). Normas sociais e racismo: efeitos do individualismo meriocrático e do igualitarismo nainfra- humanização dos negros. Tese de doutorado não-publicada, Instituto Superior de Ciência do Trabalho e da Empresa, Lisboa.

Lima, M. E. O., \& Vala, J. (2005). A cor do sucesso: efeitos da performance social e econômica no branqueamento e na infra-humanização. Psicologia USP, 16 (3), 120-131.

Lima, M. E. O., Pinheiro, C., Pacheco, J., Lima, C., \& Vala, J. (2006). Normas sociais e preconceito: o impacto da desigualdade e da competição no preconceito automático contra negros. Psicologia Reflexão e Crítica, 19 (2), 309-319.

Maroco, J. (2003). Análise estatística com utilização do SPSS. Lisboa: Silabo.

Martinez, l., \& Camino, L. (2000, setembro). Brasil es racista, Brasil no es racista: el discurso social como determinante de las diferencias percibidas entre blanco negros y morenos. Trabalho apresentado no VII Congresso de Psicologia Social da Espanha, Oviedo, España.

Moscovici, S., \& Pérez, J. A. (1997). Prejudice and social representations. Papers on Social Representations, 6 (1), 27-36.

Moscovici, S., \& Pérez, J. A. (1999). A extraordinária resistência das minorias à pressão das maiorias: o caso dos ciganos. In J. Vala (Coord.), Novos racismos: perspectivas comparativas (pp.103-119). Oeiras: Celta.

Pereira, A. S. L. S. (2004). Representações sociais do homossexualismo e preconceito contra homossexuais. Dissertação de mestrado não-publicada, Universidade Católica de Goiás, Goiânia.

Pereira, C., \& Soares, A. (2003a). Reflexões acerca da perspectiva das representações sociais. Revista Estudos, $30(1), 61-83$

Pereira, C., Torres, A. R. R., \& Almeida, S. T. (2003b). O estudo do preconceito na perspectiva das representações sociais: análise da influência de um discurso justificador da discriminação no preconceito racial. Psicologia: Reflexão e Crítica, 16 (1), 95-107.

Pettigrew, T. F., \& Meertens, R. W. (1995). Subtle and blatant prejudice in Western Europe. European Journal of Social Psychology, 25 (1), 461-476. 
Rios, R. R. (2002). OPrincípio da igualdade e a discriminação por orientação sexual:a homossexualidade no direito brasileiroe norte-americano. São Paulo: Revista dos Tribunais.

Spencer, C. (1999). Homossexualidade: uma história (2a. ed). Rio de Janeiro: Record.

Sroufe A. L. (1979). Socioemotional development. In J. D. Osofsky (Ed.), Handbook of infant development (pp. 462-516). New York: Wiley.

Struch, N., \& Schwartz, S. H. (1989). Intergroup agression: predictors and distinctiveness from intergroup bias. Journal of personality and Social Psychology, 56 (3), 364-373.

Tabachnick, B. G., \& Fidel, L. S. (1996). Using multivariate statistics. New York: Harper Collins.
Vala, J., Brito, R., \& Lopes, D. (1998). Expressões dos racismos em Portugal. Lisboa: Instituto de Ciências Sociais da Universidade de Lisboa.

Vala, J., Brito, R., \& Lopes, D. (1999). O racismo flagrante e o racismo sutil em Portugal. In J. Vala (Org.), Novos racismos: perspectivas comparativas (pp.31-59). Oeiras: Celta.

Venturi, G., \& Paulino, M. F. (1995). Pesquisando preconceito racial. In C. Turra \& G. Venturi (Orgs.), Racismo cordial: a mais completa análise sobre o preconceito de cor no Brasil (pp.83-95). São Paulo: Ática.

Recebido em: 16/1/2007

Versão final reapresentada em: 13/4/2007

Aprovado em: 3/5/2007 